\title{
A RECEPÇÃO PELO ORDENAMENTO BRASILEIRO DOS TRATADOS DE DIREITOS HUMANOS CONTRA A TORTURA E OUTROS TRATAMENTOS OU PENAS CRUÉIS, DESUMANOS OU DEGRADANTES
}

\section{RECEPTION BY BRAZILIAN PLANNING RIGHTS OF TREATED HUMAN AGAINST TORTURE AND OTHER CRUEL, INHUMAN OR DEGRADING}

\begin{abstract}
Cleide Aparecida Gomes Fermentão
Doutora em Direito das relações sociais pela UFPR-Universidade Federal do Paraná; Mestre em Direito Civil e graduação pela UEM-Universidade Estadual de Maringá; professora do Programa de Mestrado e da graduação da CESUMAR. Centro Universitário de Maringá; Professora da EMAP -Escola da Magistratura do Estado do Paraná; Membro do Instituto dos Advogados do Estado do Paraná. Pesquisadora do ICETI UNICESUMAR. Advogada.

E-mail: cleidefermentao@gmail.com

Leticia Facci de Castro

Mestre em Direitos da Personalidade e seu alcance na contemporaneidade pelo Centro Universitário de MaringáUNICESUMAR, Maringá-PR. Pós-graduanda em direito notarial e registral pela LFG. Graduação pelo Centro Universitário de Maringá - UNICESUMAR, Maringá-PR. Advogada regularmente inscrita na OAB/PR 86.511. Assessora jurídica no Registro de Imóveis de Sarandi-PR E-mail: leticiafaccidecastro@ hotmail.com
\end{abstract}

Recebido em: 21/06/2018 Aprovado em: 15/01/2019

RESUMO: A partir do momento em que um Estado demonstra o interesse em participar de um tratado internacional, é de extrema importância que este manifeste a sua vontade e, conforme a legislação brasileira, realize todo o processo para de fato internalizar o documento internacional. Após a ratificação, conforme a Convenção de Viena de 1969, não há que se falar em recusa no cumprimento do tratado, sob a justificativa de incompatibilidade interna com o ordenamento, uma vez que para o direito internacional, este se sobrepõe ao ordenamento interno. No ano de 1984, houve a celebração pela ONU da Convenção contra a tortura e outros tratamentos ou penas cruéis, desumanos ou degradantes, como um meio de proteção a todos aqueles que passavam por este tipo de situação. Não obstante, no Brasil, vigorava já nesta época a Lei no 6683/79, a qual concedia a anistia a todos aqueles que cometeram crimes políticos e conexos a estes, dentro da data estipulada pela mesma. O objetivo da pesquisa refere-se ao esclarecimento sobre a adesão de tratados internacionais por manifestação de vontade do Estado, e o seu não cumprimento integral pelo próprio ordenamento jurídico, uma vez que existem ditames normativos que não coincidem com a Convenção ratificada, e sua consequente responsabilização internacional. A metodologia proposta para a realização será por meio da pesquisa bibliográfica e documental, utilizando o método dialético, promovendo uma distinção das etapas de um tratado e a sua aplicação no caso concreto, com o intuito de melhor analisar o tema.

Palavras-chave: Anistia. Tratados Internacionais. Responsabilidade do Estado. 


\begin{abstract}
From the moment in which a State demonstrates interest in participating in an International Agreement, it is extremely important to demonstrate it, and, under the International Law, carry out the process to actually internalize the International document. After ratification, according to the 1969 Vienna Convention, there is no need to talk about refusing in an agreement compliance , under the international mismatch justification with the system, since the International Law overlaps the internal order. In 1984, there was a celebration by the UN Convention against torture and other cruel, inhuman or degrading treatment as a way of protecting all those who passed through this kind of situation. Nevertheless, in Brazil, the Law $n^{\circ} 6683 / 7$ gave amnesty to all those who had committed political crimes and related to them, within the time stipulated by it. The purpose of this research refers to the accession agreement clarification by State will manifestation, and its non full compliance by the Judicial System, since there are regulatory dictates that do not match the ratified Convention and its consequent International accountability. The proposed methodology for it will be through bibliographical and documentary research, using the dialectical method, promoting a distinction between stages of an agreement and its concrete application, with the objective of better analyzing the issue.
\end{abstract}

Keyword: Amnesty. International Agreement. State Responsibility.

\title{
INTRODUÇÃO
}

Desde os mais remotos tempos, a tortura se destacou como uma das formas mais degradantes de violação dos direitos humanos e da própria dignidade. Diversos episódios tornaramse incontroversos na história, e em consideração a isto, a primeira Convenção específica da ONU foi justamente sobre o tema, criando ainda, o Comitê contra a Tortura para as investigações.

No ano de 1989, o Brasil ratificou esta Convenção, bem como editou a lei no 9.455/97, exemplificando o que viria a ser a tortura no âmbito interno da jurisdição. Ocorre que, a partir de 1984, já vigorava no Brasil a lei da anistia, que caminhava em sentido contrário às garantias da dignidade humana conferidas pela Convenção.

A presente pesquisa retrata a seguinte questão: a partir do momento em que um Estado adere a um dispositivo internacional com a sua plena manifestação de vontade, qual o motivo que o leva a manter uma norma interna que não se adequa a este? Ainda, depois da revalidação da lei da anistia pelo Supremo Tribunal Federal, bem como do julgamento da ADPF $\mathrm{n}^{\mathrm{o}} 153$, qual a posição brasileira em relação à Convenção ratificada, posteriormente à lei em comento?

O objetivo desta, se baseia na construção de uma visão crítica a respeito da incompatibilidade da lei da anistia com a Convenção contra a tortura e outros tratamentos e penais cruéis, uma vez que aquela foi criada em um contexto de extrema violação de direitos humanos e da dignidade da pessoa humana, princípio que norteia todo o ordenamento jurídico vigente até hoje.

\section{RECEPÇÃO PELO ORDENAMENTO BRASILEIRO DOS TRATADOS DE DIREITOS HUMANOS CONTRA A TORTURA E OUTROS TRATAMENTOS OU PENAS CRUÉIS, DESUMANOS OU DEGRADANTES}

Para um início de discussão, convém situar o contexto histórico que acabou gerando a lei em comento, abrindo então, uma lacuna no ordenamento jurídico em relação à proteção dos direitos humanos violados neste período, bem como a recepção posterior da Convenção contra a tortura e 
outros tratamentos ou penas cruéis, desumanos ou degradantes, incorporada no ordenamento jurídico juntamente com a lei $\mathrm{n}^{\circ} 6.683 / 79$.

\section{O SURGIMENTO DA ANISTIA E O FIM DA PROTEÇÃO DOS DIREITOS HUMANOS}

Dentro do contexto brasileiro à época, a anistia consistiu em uma espécie de perdão a todos aqueles que cometeram crimes políticos e conexos durante o período de 2 de setembro de 1961 a 15 de agosto de 1979. Apenas os que já haviam sido condenados pelos crimes cometidos (como a prática de terrorismo, assalto, sequestro e atentado pessoal) ficaram de fora da lei.

Analisando o tema em um primeiro momento, cumpre conceituar e contextualizar a anistia dentro do Estado brasileiro e os atos que validaram esta, a qual foi recepcionada por diversos estados latino-americanos, cada qual à sua maneira, em momentos em que os países se encontravam em transições democráticas. ${ }^{1}$ Nestes, é possível uma percepção por meio das decisões proferidas pela Corte Interamericana de Direitos Humanos ${ }^{2}$, que a anistia se tornou uma maneira de inércia diante da responsabilização por parte do Estado, dos violadores de direitos, bem como da dignidade da pessoa humana.

Diante de uma América Latina conturbada por governos ditatoriais, o Brasil, no período compreendido entre 1964 a 1985, enfrentou um regime militar conhecido pelas suas fases de extremo desrespeito e violação a todos os direitos inerentes à pessoa humana. Violações estas, que passaram desde a vedação à liberdade na imprensa, a desaparecimentos forçados e diversos casos de denúncia contra torturadores. O ano de 1968 foi um período conhecido como "anos de chumbo", em que as repressões, bem como as violações dos direitos humanos, chegaram ao seu mais alto grau, sob a vigência do AI-5, que suspendeu diversas garantias constitucionais. Neste momento, passou-se a tornar comum o desaparecimento de todos aqueles que eram contrários ao regime. Conforme registros da Comissão Especial Sobre Mortos e Desaparecidos Políticos,

é certo que nos três primeiros anos de Geisel, os interrogatórios mediante tortura e a eliminação física dos opositores políticos continuaram sendo rotina. O desaparecimento de presos políticos, que antes era apenas uma parcela das mortes ocorridas, torna-se regra predominante para que não ficasse estampada a contradição entre discurso de abertura e a repetição sistemática das velhas notas oficiais simulando atropelamentos, tentativas de fuga e falsos suicídios. ${ }^{3}$

Com uma população descontente, passaram a surgir movimentos isolados pelo país, que possuíam a intenção de acabar com o regime militar e tomar o poder. O caso mais conhecido entre estes, é a intitulada "Guerrilha do Araguaia", que resultou no desaparecimento forçado, detenção arbitrária e tortura de mais de 70 pessoas.

Sobre o contexto histórico deste caso, diz a Comissão Especial sobre Mortos e Desaparecidos Políticos que:

\footnotetext{
${ }^{1}$ MAZZUOLI, Valério de Oliveira. Curso de Direitos Humanos. São Paulo: Método, 2014, p. 267.

${ }^{2}$ Por exemplo, nos casos Barrios Altos vs. Peru, Almonacid Arellano e outros vs. Chile (2006) e Gomes Lund e outros vs. Brasil (2010).

${ }^{3}$ BRASIL. Secretaria Especial dos Direitos Humanos. Direito à verdade e à memória: Comissão Especial sobre Mortos e Desaparecidos Políticos. Brasília: Comissão Especial Sobre Mortos e Desaparecidos Políticos, 2007.
} 
No final de 1973, último ano de Médici, já estava evidente o esgotamento do chamado "Milagre Brasileiro", ciclo de cinco anos com forte crescimento do PIB, e os grupos militares de origem castellista conseguiram recuperar força, impondo Ernesto Geisel como próximo presidente. No momento de sua posse, em março de 1974, os órgãos de repressão já tinham logrado êxito no combate aos grupos de guerrilha urbana e desenvolviam a última campanha militar de aniquilamento contra os militantes do PCdoB no Araguaia. ${ }^{4}$

No governo do presidente general Ernesto Geisel, houve uma mobilização por parte da oposição para que a anistia "ampla, geral e irrestrita" fosse concedida a todos aqueles considerados presos políticos, exilados e cassados. Durante o governo sucessor de João Figueiredo, no ano de 1979, foi concedida anistia a todos aqueles que estavam envolvidos em crimes políticos e conexos a este, no período estipulado pelo mesmo. Esta, em sua interpretação literal, deu a absolvição a todos os agentes que cometeram violações aos direitos humanos, presos e exilados políticos. ${ }^{5}$

Trata-se de uma espécie de autoanistia do próprio regime, de modo que não existisse uma perseguição nas violações que ocorreram em todo o território.

De acordo com o artigo primeiro da lei $n^{\circ} 6.683 / 79^{6}$, apenas aqueles que se encontravam condenados no momento da criação da lei, não seriam abrangidos pelos benefícios concedidos pela anistia. $^{7}$

\section{A POSTURA INTERNACIONAL E A COMISSÃO CONTRA A TORTURA}

Diante de uma série de violações aos direitos humanos que, infelizmente, ocorrem ao redor de todo o mundo desde os tempos mais remotos, pode-se dizer que a tortura é uma das formas mais repugnantes e degradantes que um humano pode ser sujeitado. Esta possui um efeito negativo de maneira tão forte aos envolvidos, que foi alvo da primeira Convenção internacional que trata um assunto em especifico, como uma forma de proteção aos direitos humanos e a própria dignidade do ser.

No ano de 1984, foi celebrada pela ONU a Convenção contra a tortura e outros tratamentos ou penas cruéis, desumanos ou degradantes, fazendo com que todos aqueles que passavam ou passam por qualquer tipo de danos para a sua dignidade recebessem uma atenção especial no quesito proteção e punibilidade do agente ativo. Ainda, foi criado o Comitê contra a Tortura, para investigar qualquer denúncia ou iminência desta.

\footnotetext{
${ }^{4}$ Ibidem.

5 Ibidem, p. 33.

${ }^{6}$ BRASIL. Lei $n^{\circ}$ 6.683, de 28 de agosto de 1979. Concede anistia e dá outras providências. Disponível em: <http://www.planalto.gov.br/ccivil_03/leis/L6683.htm> Acesso em 14 de jul de 2016. Art. $1^{\circ}$ É concedida anistia a todos quantos, no período compreendido entre 02 de setembro de 1961 e 15 de agosto de 1979, cometeram crimes políticos ou conexo com estes, crimes eleitorais, aos que tiveram seus direitos políticos suspensos e aos servidores da Administração Direta e Indireta, de fundações vinculadas ao poder público, aos Servidores dos Poderes Legislativo e Judiciário, aos Militares e aos dirigentes e representantes sindicais, punidos com fundamento em Atos Institucionais e Complementares (vetado). $\S 1^{\circ}$ - Consideram-se conexos, para efeito deste artigo, os crimes de qualquer natureza relacionados com crimes políticos ou praticados por motivação política. $\S 2^{\circ}$ - Excetuam-se dos benefícios da anistia os que foram condenados pela prática de crimes de terrorismo, assalto, seqüestro e atentado pessoal. $\S 3^{\circ}$ - Terá direito à reversão ao Serviço Público a esposa do militar demitido por Ato Institucional, que foi obrigada a pedir exoneração do respectivo cargo, para poder habilitar-se ao montepio militar, obedecidas as exigências do art. $3^{\circ}$

${ }^{7}$ CASTILHO, Ricardo. Direitos Humanos. São Paulo: Saraiva, 2012, p. 229.
} 
O texto da Convenção pode ser dividido em partes, de maneira que os sujeitos ativos e passivos sejam identificados, bem como sejam delimitados os procedimentos a serem realizados após a sua adesão, a formação de um comitê e o seu funcionamento, e por fim, a adesão dos Estados à Convenção. ${ }^{8}$

Os artigos $3^{\circ}$ e $4^{\circ}$ são pontos interessantes da Convenção. Estes destacam a possibilidade de responsabilização do Estado em razão dos atos realizados pelos funcionários públicos, mesmo que diante de ordens superiores.

Ao todo foram 24 artigos que a compuseram, e não mais fizeram do que esclarecer todo e qualquer procedimento que deverá ser tomado em casos de tortura ou tratamentos degradantes. Ainda ressaltou que não existem possibilidades de justificativas em situações como esta, até mesmo em casos de guerra - conforme o artigo $5^{\circ}$ da mesma.

É de extrema importância ressaltar que, como forma de manter o tratamento igualitário no procedimento, assim como todos os direitos pessoais e intransferíveis do ser humano, as garantias processuais do suposto autor do delito em questão não foram retiradas pela Convenção, assim, todos os princípios constitucionais e protetores da dignidade humana devem ser respeitados. A jurisdição interna dos países aderentes não foi excluída.

Como exemplo dessa continuidade dos princípios internos compatíveis com a Convenção, conforme o artigo 13, os delitos ressaltados nesta são passíveis de extradição, mesmo entre um Estado parte e aquele com o qual não tiver tratado, vigendo aqui, o princípio da universalidade. A Convenção será o suporte para o procedimento da extradição.

Em 1989 o Brasil ratificou a Convenção, e editou a lei $n^{\circ}$ 9.455/97, que exemplificou o que se entendia por tortura no âmbito interno da jurisdição ${ }^{9}$, o demonstra um caminho expressamente contraditório ao estabelecido nos ditames sobre a concessão da anistia.

Conforme uma comparação direta com a Convenção é possível verificar que foi ampliado o sujeito ativo, de modo que qualquer pessoa que realizar um ato atentatório a outrem, possa ser enquadrada neste.

Com o advento da Constituição de 1988, antes mesmo da ratificação do tratado, passouse a priorizar a dignidade da pessoa humana, como um dos fundamentos basilares de todo o

${ }^{8}$ PLANALTO. Presidência da república casa civil subchefia para assuntos jurídicos. Disponível em: <http://www.planalto.gov.br/ccivil_03/decreto/1990-1994/d0040.htm>. Acesso em: 31 ago. 2016.

${ }^{9}$ Conforme a referida lei, o crime de tortura pode ser definido como: Art. $1^{\circ}$ Constitui crime de tortura:

I - Constranger alguém com emprego de violência ou grave ameaça, causando-lhe sofrimento físico ou mental:

a) com o fim de obter informação, declaração ou confissão da vítima ou de terceira pessoa; b) para provocar ação ou omissão de natureza criminosa; c) em razão de discriminação racial ou religiosa; II - submeter alguém, sob sua guarda, poder ou autoridade, com emprego de violência ou grave ameaça, a intenso sofrimento físico ou mental, como forma de aplicar castigo pessoal ou medida de caráter preventivo. Pena - reclusão, de dois a oito anos. $\mathrm{m} \S 1^{\circ} \mathrm{Na}$ mesma pena incorre quem submete pessoa presa ou sujeita a medida de segurança a sofrimento físico ou mental, por intermédio da prática de ato não previsto em lei ou não resultante de medida legal. $\S 2^{\circ}$ Aquele que se omite em face dessas condutas, quando tinha o dever de evitá-las ou apurá-las, incorre na pena de detenção de um a quatro anos. $\S 3^{\circ}$ Se resulta lesão corporal de natureza grave ou gravíssima, a pena é de reclusão de quatro a dez anos; se resulta morte, a reclusão é de oito a dezesseis anos. $\S 4^{\circ}$ Aumenta-se a pena de um sexto até um terço: I - se o crime é cometido por agente público; II - se o crime é cometido contra criança, gestante, portador de deficiência, adolescente ou maior de 60 (sessenta) anos; (Redação dada pela Lei n. 10.741, de 2003)

III - se o crime é cometido mediante sequestro. $\S 5^{\circ} \mathrm{A}$ condenação acarretará a perda do cargo, função ou emprego público e a interdição para seu exercício pelo dobro do prazo da pena aplicada. $\S 6^{\circ} \mathrm{O}$ crime de tortura é inafiançável e insuscetível de graça ou anistia. $\S 7^{\circ} \mathrm{O}$ condenado por crime previsto nesta Lei, salvo a hipótese do $\S 2^{\circ}$, iniciará o cumprimento da pena em regime fechado. 
ordenamento jurídico brasileiro, fazendo com que, conforme o artigo $5^{\circ}$, III da $\mathrm{CF} / 88$, a tortura entrasse para o rol dos crimes hediondos, tornando-a insuscetível de fiança, graça ou anistia. $\mathrm{O}$ referido dispositivo constitucional possui a previsão de que "ninguém será submetido a tortura ou a tratamento desumano ou degradante".

Aqui, o ordenamento parecia estar se adequando aos ditames internacionais, deixando para trás um período ditatorial e violador de direitos humanos.

\section{TRATADOS INTERNACIONAIS: A RECEPÇÃO VOLUNTÁRIA, A SUA NECESSÁRIA VINCULAÇÃO DEPOIS QUE SÃO RATIFICADOS E O CONTROLE INTERNACIONAL}

Para que uma norma entre em nosso ordenamento jurídico de maneira válida, deve existir outra como fundamento. As normas encontram-se em uma ordem hierárquica - a pirâmide normativa - que acaba por delimitar os limites materiais e formais do poder normativo. Nas palavras deVitor Hugo Nicastro Honesko, se examinarmos a pirâmide normativa de baixo para cima, perceberemos que as normas jurídicas inferiores se encontram fundadas, material e formalmente, em normas jurídicas superiores, da mesma maneira ocorre quando ao contrário. ${ }^{10}$

Aqui entram os tratados de direitos humanos no nosso ordenamento, os quais devem sempre ingressar neste, por meio de uma norma superior. ${ }^{11}$ A partir do momento em que o Estado realiza a ratificação do tratado de direitos humanos, todo o seu conjunto de normas integram as garantias e direitos protegidos constitucionalmente, devendo então, ter a sua aplicação.

Conforme a Constituição de 1988, o Estado pode realizar sua participação no direito internacional, mediante um procedimento que necessita da manifestação de vontade dos poderes Executivo e Legislativo na matéria dos tratados: é a teoria da junção das vontades. Aqui, verificase que caso esta manifestação de vontade não exista, não há que se falar em formação de tratados e seu cumprimento interno. ${ }^{12}$

Para a celebração definitiva de um tratado, fases devem ser cumpridas. Em primeiro lugar, como forma de demonstração de vontade, tem-se a fase da assinatura, na qual acontecem todas as negociações sobre o conteúdo do tratado, que resulta na manifestação expressa do interesse na celebração. Apenas após estas, o tratado é incorporado e acontece o decreto presidencial.

Como não existe prazo estipulado para a aprovação congressual, o trâmite pode durar até décadas, dependendo, infelizmente, da conveniência política. Para a celebração definitiva do mesmo, também não há prazo para o Presidente da República, o que faz com que a sua ratificação não seja obrigatória, e sim um ato discricionário.

A norma internacional não será válida ainda, enquanto não for editado o Decreto de Promulgação pelo Presidente da República e referendado pelo Ministro das Relações Exteriores. Neste momento, é incorporado ou recepcionado o tratado internamente. A este respeito, André de Carvalho Ramos destaca:

\footnotetext{
${ }^{10}$ HONESKO, Vitor Hugo Nicastro. A proibição da tortura no âmbito global e seu impacto no sistema jurídico brasileiro. In: PIOVESAN, Flávia; IKAWA, Daniela. Direitos Humanos: Fundamento, proteção e implementação. Curitiba: Juruá, 2010. Cap. 3. p. 289-305.

11 ibidem. p. 300.

${ }^{12}$ RAMOS, André de Carvalho. Curso de Direitos Humanos. São Paulo: Saraiva, 2014. p.360.
} 
Esse Decreto inova a ordem jurídica brasileira, tornando válido o tratado no plano interno. Não há prazo para sua edição e até lá o Brasil está vinculado internacionalmente, mas não internamente: esse descompasso enseja a óbvia responsabilização internacional do Brasil. $^{13}$

Desta forma, verifica-se a complexidade de incorporação de um tratado internacional, e a necessidade de manifestação de vontade para que as negociações se iniciem. Assim, não há que se falar de um tratado imposto dentro do ordenamento, o que implica sua obrigatoriedade de cumprimento.

Ademais, para o âmbito internacional, todos os atos normativos internos de um Estado devem ser compatibilizados com os compromissos assumidos, sob pena de responsabilização, uma vez que um estado não pode se escusar a cumprir determinada norma sob a argumentação de uma incompatibilidade interna, conforme o art. 27 da Convenção de Viena sobre o Direito dos Tratados, de 1969.

Em consonância com a compatibilidade interna das normas com o direito internacional, é importante ressaltar ainda que há outra forma de verificação se um tratado está devidamente sendo cumprido: o controle de convencionalidade. Esse consiste em uma análise realizada internamente nos países em relação às normas internacionais, quanto à compatibilidade dos atos internos destes, sejam comissivos ou omissivos. André de Carvalho Ramos realiza uma subdivisão deste controle em: convencionalidade de matriz internacional - aquele que é competência dos órgãos internacionais e é realizado pelos tribunais internacionais - e o de convencionalidade de matriz nacional - consistente no exame das normas internacionais realizado pelos juízes internos. ${ }^{14}$

Em outras palavras, controle de convencionalidade internacional será aquele no qual há uma fiscalização dos atos do Estado, por órgãos internacionais, em relação aos compromissos assumidos internacionalmente. Já o controle de convencionalidade nacional é a verificação da compatibilidade das normas internacionais, dentro do ordenamento interno. É de suma importância salientar que o controle nacional não vincula o internacional. ${ }^{15}$

É certo que não serão todas as vezes que o controle de convencionalidade internacional coincidirá com o interno, como é o caso da Lei da Anistia, conforme os dizeres do referido autor:

É óbvio que nem sempre os resultados do controle de convencionalidade internacional coincidirão com os do controle nacional. Por exemplo, um Tribunal interno pode afirmar que determinada norma legal brasileira é compatível com um tratado de direitos humanos; em seguida, um órgão internacional de direitos humanos, ao analisar a mesma situação, pode chegar à conclusão de que a referida lei viola o tratado. ${ }^{16}$

Em virtude de uma possível contrariedade de entendimentos diante de uma situação concreta, o controle de constitucionalidade final é o internacional, e deste decorre uma segunda denominação como "controle autêntico ou definitivo", uma vez que é desta maneira que se chega à premissa de que o tratado foi devidamente cumprido.

\footnotetext{
${ }^{13}$ RAMOS, André de Carvalho. Curso de Direitos Humanos. São Paulo: Saraiva, 2014. p 360.

${ }^{14}$ Ibidem. p. 386, 387.

${ }^{15}$ RAMOS, André de Carvalho. Teoria geral dos direitos humanos na ordem internacional. $2^{\mathrm{a}}$ ed. São Paulo: Saraiva, 2012. P 74.

16 _ Curso de Direitos Humanos. São Paulo: Saraiva, 2014, p. 630.
} 
Assim sendo, sob a visão do direito internacional todos os atos normativos internos de um país, são vontades que devem ser compatíveis com os seus engajamentos internacionais, de maneira que o Estado não poderá alegar que houve um descumprimento de norma internacional, devido à incompatibilidade com o ordenamento interno. Há uma supremacia de normas. ${ }^{17}$

\section{CASO GOMES LUND - O RECONHECIMENTO DA RESPONSABILIDADE BRASILEIRA E A FALTA DE ADEQUAÇÃO DAS DECISÕES COM A CONVENÇÃO INTERNACIONAL RATIFICADA}

De acordo com o contido na Jurisprudência da Corte Interamericana de Direitos Humanos, o caso refere-se à responsabilidade do Estado pela - nas próprias palavras do julgado:

detenção arbitrária, tortura e desaparecimento forçado de 70 pessoas, entre membros do partido comunista e camponeses da região, resultado de operações do Exército brasileiro empreendidas entre 1972 e 1975 com o objetivo de erradicar a Guerrilha do Araguaia, no contexto da ditadura militar. ${ }^{18}$

Tal movimento consistia na construção de um exército popular contra o regime vigente, o qual foi combatido pelo exército, marinha, forças aéreas e polícia militar e federal. Em um primeiro momento a ordem era apenas para conter os integrantes do movimento, mas, sob as ordens do general Médice, a ordem oficial passou a ser de eliminação dos capturados. Ao final do ano de 1974, não havia mais guerrilheiros no Araguaia, e ainda, constam em registros que os corpos foram desenterrados e queimados ou atirados no rio da região. ${ }^{19}$

O governo impôs silencio no caso.

Na data de 18 de Julho de 2006, o Grupo Tortura Nunca Mais do Rio de Janeiro, a Comissão de Familiares de Mortos e Desaparecidos Políticos do Instituto de Estudos da Violência do Estado e o Centro pela Justiça e o Direito Internacional, apresentaram suas solicitações e provas em relação aos desaparecimentos forçados e à impunidade do Estado frente a estas.

O Estado, por sua vez, interpôs três exceções preliminares, sendo a incompetência do tribunal para examinar a demanda, devido ao tempo dos fatos; o não esgotamento dos recursos internos; o não interesse processual da Comissão e de seus representantes. Ainda, contestou a demanda.

A Corte considerou que a partir do momento em que o Brasil reconheceu a competência contenciosa da Corte Interamericana, esta teria competência para decidir sobre fatos posteriores.

Em sua verificação, a Corte constatou graves violações de direitos humanos no caso do Araguaia, uma vez que os desaparecimentos forçados ferem os princípios do Sistema Interamericano de Direitos Humanos, de forma que foi alcançado um caráter de jus cogens no caso.

Cumpre ressaltar que, em momento algum foi negado pelo Estado o desaparecimento das vítimas, mas sim controvérsias a respeito da Convenção Americana sobre Direitos Humanos, a

\footnotetext{
17 ibidem. P. 387.

${ }^{18}$ CORTE INTERAMERICANA DE DIREITOS HUMANOS. Caso gomes lund e outros ("guerrilha do araguaia") vs. Brasil. Disponível em:< http://www.corteidh.or.cr/docs/casos/articulos/seriec_219_por.pdf>. Acesso em: 31 ago. 2016. P. 3.

19 JUSTIÇA, Biblioteca do Ministério da; JANEIRO, Núcleo de Direitos Humanos do Departamento de Direito da Pontifícia Universidade Católica do Rio de (Org.). Jurisprudência da Corte Interamericana de direitos humanos: direito à vida, anistias e direito à verdade. Rio de Janeiro: Prol Editora Gráfica, 2014. P. 33.
} 
qual teve a sua ratificação pelo Estado brasileiro em 1992, dando plenos poderes para uma averiguação da compatibilidade da lei da anistia.

O Estado brasileiro procurou formas de reparação do ocorrido, dentre elas a promulgação da Lei $\mathrm{n}^{\circ}$ 9.140/95 e a publicação do direito à memória e à verdade, mas, segundo a Comissão, estas não foram suficientes para o caso em questão.

Por fim, foi decidido com unanimidade pela Corte que todos os efeitos causados pela lei da anistia não podem ser considerados obstáculos para as investigações, assim como a mesma fere as convenções ratificadas pelo Estado brasileiro.

Em relação à responsabilidade sobre o caso Araguaia, foi reconhecida a responsabilidade do Estado nas violações de direitos humanos ocorridas, bem como da dignidade humana, todos os atos foram contrários aos dispostos nas convenções. Por unanimidade foi disposto que o estado não deveria medir esforços para realizar as buscas e investigações das vítimas, bem como oferecer todo o suporte necessário para os seus familiares, sejam tratamentos médicos ou psiquiátricos, realizar um ato público para reconhecer a sua responsabilidade e não deixar de realizar novas buscas para esclarecimento dos familiares.

A Corte foi clara ao dar o seu parecer, afastando os efeitos da lei da anistia, uma vez que esta feria diretamente todos os tratados e convenções ratificados pelo Estado brasileiro, reconhecendo a responsabilidade integral deste no dever de reparar, e por fim, no quesito de supervisionar o fiel cumprimento da sentença. A mesma foi dada no dia 24 de novembro de 2010.

\section{A INCOMPATIBILIDADE DA CONVENÇÃO COM A LEI DA ANISTIA}

Conforme o artigo $5^{\circ}$, inciso LIV da Constituição Federal de 1988:

a anistia é ato político, concedido mediante lei, da competência do Congresso e do Chefe do Executivo, correndo por conta destes a avaliação dos critérios de conveniência e oportunidade do ato, sem dispensa, entretanto, do controle judicial, porque pode ocorrer, por exemplo, desvio do poder de legislar ou afronta ao devido processo legal substancial.

Em meio a um período de regime militar, onde os casos de tortura eram cada vez mais frequentes e conhecidos, no ano de 1979 foi promulgada no Brasil a Lei $n^{\circ}$ 6.683/79, a lei da anistia.

Essa trouxe uma possibilidade de anistia a todos aqueles que realizaram crimes políticos ou conexos a estes no período de setembro de 1961 a agosto de 1979, de modo que todos os procedimentos penais envolvidos nos casos ficaram impedidos de realização. A mesma não foi nada mais que uma forma de controle do governo, bem como uma espécie de tentativa de redemocratização na época. ${ }^{20}$

No ano de 1984, a Convenção contra a tortura e outros tratamentos e penas cruéis, desumanas ou degradantes, era ratificada pelo Brasil, ainda sob a vigência da lei. Sucede que, com a chegada da Constituição de 1988, e um Estado democrático de direito, incompatibilidades com a anistia concedida foram surgindo, bem como a contrária disposição desta com a Convenção e suas disposições expressas.

\footnotetext{
${ }^{20}$ HUMANOS, Secretaria Especial dos Direitos. Direito á verdade e á memória: Comissão Especial sobre Mortos e Desaparecidos Políticos. Brasília: Comissão Especial Sobre Mortos e Desaparecidos Políticos, 2007. P. 23. (Bibliográfica).
} 
Em primeiro lugar, cumpre retomar um ponto pertinente à discussão para o direito internacional, uma vez que o Estado assumiu um compromisso perante este, e não há possibilidades de ressalvas quanto à obrigatoriedade em seu cumprimento, inclusive quando são utilizadas "desculpas com base na Constituição" ou ordenamento interno. Sob este argumento, o Supremo entendeu que a lei da anistia era constitucional, criada em um específico contexto histórico, sem possibilidade de revogação.

Mesmo diante de uma ADPF (ADPF n 153, rel. Min. Eros Grau), a lei não foi retirada do ordenamento jurídico, com os seus efeitos até os dias de hoje. Nos questionamentos feitos por esta, encontravam-se a recepção da lei da anistia pela Constituição de 1988, de modo que a norma tivesse sua interpretação literal afastada, sendo então, analisada sob a ótica constitucional. ${ }^{21}$

O Supremo considerou, ainda, que se trata de um ato bilateral, com a participação da sociedade, e, conforme a previsão na Emenda Constitucional $n^{\circ} 26 / 85$, em seu artigo $4^{\circ}, \S^{\circ}$, a validação da lei ocorreu, gerando também a recepção pela Constituição de 1988.

$4^{\circ}$ É concedida anistia a todos os servidores públicos civis da Administração direta e indireta e militares, punidos por atos de exceção, institucionais ou complementares.

$\S 1^{\circ}$ É concedida, igualmente, anistia aos autores de crimes políticos ou conexos, e aos dirigentes e representantes de organizações sindicais e estudantis, bem como aos servidores civis ou empregados que hajam sido demitidos ou dispensados por motivação exclusivamente política, com base em outros diplomas legais.

Em seus dizeres sobre a ADPF, o relator Ministro Eros Grau, durante o seu voto, ressalta que:

A chamada Lei da Anistia veicula uma decisão política assumida naquele momento - o momento da transição conciliada de 1979. A Lei 6.683 é uma lei-medida, não uma regra para o futuro, dotada de abstração e generalidade. Há de ser interpretada a partir da realidade no momento em que foi conquistada. A Lei 6.683/1979 precede a Convenção das Nações Unidas contra a Tortura e Outros Tratamentos ou Penas Cruéis, Desumanos ou Degradantes - adotada pela Assembleia Geral em 10 de dezembro de 1984, vigorando desde 26 de junho de 1987 - e a Lei 9.455, de 7 de abril de 1997, que define o crime de tortura; e o preceito veiculado pelo art. $5^{\circ}$, XLIII, da Constituição - que declara insuscetíveis de graça e anistia a prática da tortura, entre outros crimes - não alcança, por impossibilidade lógica, anistias anteriormente a sua vigência consumadas. A Constituição não afeta leis-medida que a tenham precedido. ${ }^{22}$

As violações aos direitos humanos ocorridos pelo período "protegido" pela lei da anistia não se tratam de um fato controverso e esta lei, logo em seu primeiro artigo, demonstra uma incompatibilidade com a Convenção e com a Constituição brasileira, a qual não mencionou, em qualquer momento, o instituto, mas sim uma importância à punição de qualquer violação de direitos humanos e da personalidade.

A Declaração Universal dos Direitos Humanos foi um dos acontecimentos mais importantes para a proteção dos direitos humanos, servindo como marco inicial para outros tratados

21 STF. Argüição de descumprimento de preceito fundamental 153. Distrito federal. Disponível em: <http://www.stf.jus.br/arquivo/cms/noticianoticiastf/anexo/adpf153.pdf>. Acesso em: 31 ago. 2016.

22 STF. Argüição de descumprimento de preceito fundamental 153 distrito federal. Disponível em: <http://www.stf.jus.br/arquivo/cms/noticianoticiastf/anexo/adpf153.pdf〉. Acesso em: 31 ago. 2016.p. 50. 
com finalidades conexas, passando, então, a existir uma movimentação mundial de proteção de tais direitos.

No momento em que um país atravessa um período de exceção, as violações, infelizmente, tornam-se frequentes e ocorrem nas suas mais variadas formas. Mesmo com um grande número de convenções para resguardar tais direitos, ocorrendo desde 1948 (momento em que surgiu a declaração universal dos direitos humanos), o Brasil passou a ratificar de maneira tardia os mesmos, o que fez com que uma grande demanda de ações que possuíam não apenas o intuito de reparação, mas de esclarecimento sobre os ocorridos chegassem ao judiciário e ao âmbito internacional.

O caso mais emblemático, em relação ao Brasil, foi o já mencionado Caso Gomes Lund ou Guerrilha do Araguaia, no qual a Corte Interamericana julgou a invalidade da lei de anistia e determinou a punição dos responsáveis pelos crimes ocorridos.

Mesmo diante de tal julgamento, o STF manteve a posição de que tal decisão não o vincularia, sem qualquer efeito surtido. Aqui entra o questionamento sobre a escusa de cumprimento de norma internacional ratificada, sob argumentos embasados em normas internas.

O STF, analisando a validade do dispositivo, optou pelo "caráter bilateral da anistia, ampla e geral", afirmando ainda que "o argumento descolado da dignidade da pessoa humana para afirmar a invalidade da conexão criminal que aproveitaria aos agentes políticos que praticaram crimes comuns contra opositores políticos, presos ou conexão sui generis, própria ao momento histórico da transição para a democracia. Ignora, no contexto da lei $\mathrm{n}^{\circ} 6.683 / 79$, o sentido ou os sentidos correntes na doutrina da chamada conexão criminal; refere o que "se procurou", segundo a inicial, vale dizer, estender a anistia criminal de natureza política aos agentes do Estado encarregados da repressão. A lei estendeu a conexão aos crimes praticados pelos agentes do Estado contra os que lutavam contra o Estado de exceção, a chamada lei da anistia veicula uma decisão política assumida naquele momento". 23

Países que aderiram à Convenção, bem como aqueles que também passaram por períodos transitórios em seu regime, adequaram-se às diretrizes internacionais, e se encontram em um período de incentivo ao rompimento de um passado autoritário e violador de direitos, investigando os casos conforme os pedidos de particulares. Tal procedimento nada mais é do que um incentivo à confiança do cidadão com o Estado. Já no Brasil, as adequações andam a passos lentos.

No ano de 2010, com a sentença do caso Gomes Lund e Outros, diversas imposições pela Corte foram impostas, de modo que o Brasil passasse a investigar as mortes e cumprisse, de fato, os ditames da Convenção incorporada no âmbito interno. Neste momento, foram criadas a Lei do Acesso à Informação e a Lei da Comissão Nacional da Verdade ( $\mathrm{n}^{\circ}$ 12.527/11 e 13.028/11, respectivamente), ambas com o intuito de dar publicidade e transparência nos casos ocorridos durante o regime militar, o qual causou dezenas de mortes, sem a sua devida explicação. Tais leis têm, ainda, o objetivo de evitar que estes casos se repitam.

Podemos perceber então, que mesmo diante de compromissos internacionalmente realizados pelo Brasil, internamente o seu fiel cumprimento caminha a passos lentos, uma vez que mesmo diante de uma ADPF, o STF manteve o entendimento da constitucionalidade da lei. No âmbito internacional, a Corte já deixou claro que a lei não vincula os particulares quando houver o interesse de investigações referentes a este período. Vemos então, o direito internacional

23 STF. Argüição de descumprimento de preceito fundamental 153 distrito federal. Disponível em: <http://www.stf.jus.br/arquivo/cms/noticianoticiastf/anexo/adpf153.pdf>. Acesso em: 31 ago. 2016. P. 33, 34. 
priorizando mais uma vez, a dignidade da pessoa humana, enquanto internamente, os particulares encontram-se limitados a um entendimento retrógrado do Supremo Tribunal Federal.

\section{CONCLUSÃO}

Diante da análise realizada, é possível verificar uma incongruência dentro das normas contidas no ordenamento jurídico Brasileiro. Uma vez que compromissos internacionais são assumidos, não há que se falar em normas com interesses contrários a este, principalmente quando ambos encontram-se vigentes no mesmo período.

A partir do momento em que a Lei da Anistia entrou em vigor, diversos obstáculos foram postos no caminho daqueles que foram prejudicados no período anistiado por esta. Tal situação parecia ter sido alterada, apenas quando a Convenção contra a tortura e outros tratamentos cruéis e degradantes foi ratificada pelo Brasil. Ocorre que, foi necessária uma sentença desfavorável internacionalmente para que mudanças internas passassem a acontecer de fato, fazendo com que houvesse uma proteção - mesmo que tardia - a todos aqueles que foram prejudicados direta, ou indiretamente, por um período marcado pela repressão intensa.

Segundo o STF, a lei é válida e todos os seus efeitos continuam vigorando no tempo; conforme o entendimento da corte, ela viola diretamente os direitos humanos, não podendo assim, ter sua validade. Esta aberração jurídica em nosso ordenamento, ainda gerará muitas controvérsias, seja no rito processual, seja aos pesquisadores. Resta ao Brasil adequar-se totalmente aos seus compromissos internacionais, de maneira a proteger de forma integral todos os afetados pela abertura concedida pela lei $6.683 / 79$.

\section{REFERÊNCIAS}

ÂMBITO JURÍDICO. A incorporação da convenção contra a tortura e outros tratamentos ou penas cruéis, desumanos ou degradantes pelo estado brasileiro em consonância com a justiça global. Disponível em:< http://www.ambito-

juridico.com.br/site/index.php?n_link=revista_artigos_leitura\&artigo_id=9862>. Acesso em: 20 jun. 2018.

ARBEX, Daniela. Holocausto Brasileiro: Vida, Genocídio e 60 mil mortes no maior hospício do Brasil. São Paulo: Geração, 2013.

ARNS, Dom Paulo Evaristo. Brasil: nunca mais: um relato para a história. 32. ed. Petrópolis, Rj: Vozes, 2001.

BRASIL. Supremo Tribunal Federal. Arguição de Descumprimento de Preceito Fundamental $\mathbf{n}^{\circ}$ 153. Ministro Relator Eros Grau. Arguente: Conselho Federal da Ordem dos Advogados do Brasil. Arguidos: Presidente da República e Congresso Nacional. Brasília, 29 de abril de 2010. In. Diário de Justiça Eletrônico, n. 145/2010 (06 de agosto de 2010).

CASADO FILHO, Napoleão; BIANCHINI, Alice; GOMES, Luiz Flávio. Direitos Humanos Fundamentais. São Paulo: Saraiva, 2012. 
CASTILHO, Ricardo. Direitos Humanos: Sinopses Jurídicas. São Paulo: Saraiva, 2012.

CONSULTOR JURÍDICO. A lei de anistia viola convenções de direitos humanos. Disponível em: <http://www.conjur.com.br/2011-mar-10/coluna-lfg-lei-anistia-viola-convencoes-direitoshumanos>. Acesso em: 20 jun. 2018.

DEPARTAMENTO DE ASSUNTOS JURÍDICOS INTERNACIONAIS. Convenção interamericana para prevenir e punir a tortura. Disponível em:

<http://www.oas.org/juridico/portuguese/treaties/a-51.htm>. Acesso em: 20 jun. 2018.

DIMOULIS, Dimitri Leonardo Martins. Teoria Geral dos Direitos Fundamentais. São Paulo: Revista dos Tribunais, 2007.

DIREITOS FUNDAMENTAIS.Guerra de gigantes: STF versus CIDH (lei de anistia). Disponível em: <https://direitosfundamentais.net/2011/02/17/guerra-de-gigantes-stf-versus-cidh-lei-deanistia/>. Acesso em: 31 ago. 2016.

HUMANOS, Secretaria Especial dos Direitos. Direito a verdade e a memória: Comissão Especial sobre Mortos e Desaparecidos Políticos. Brasília: Comissão Especial Sobre Mortos e Desaparecidos Políticos, 2007.

JUSTIÇA, Biblioteca do Ministério da. Conselho de defesa dos direitos da pessoa humana: uma história de resistência e luta pelos direitos humanos no Brasil. Brasília: Biblioteca do Ministério da Justiça, 2010.

JUSTIÇA, Biblioteca do Ministério da; JANEIRO, Núcleo de Direitos Humanos do Departamento de Direito da Pontifícia Universidade Católica do Rio de (Org.). Jurisprudência da Corte Interamericana de direitos humanos: direito à vida, anistias e direito à verdade. Rio de Janeiro: Prol Editora Gráfica, 2014.

JURICIC, Paulo. Crime de Tortura. São Paulo: Juarez de Oliveira, 1999. 180 p.

MAZZUOLI, Valério de Oliveira. Curso de Direitos Humanos. São Paulo: Método, 2014. 318 p.

MAZZUOLI, Valério de Oliveira. Crimes da ditadura militar: uma análise à luz da jurisprudência atual da Corte Interamericana de Direitos Humanos. São Paulo: Revista dos Tribunais, 2011.

MIRANDA, Pontes de. Comentários à Constituição de 1967, tomo I. Revista dos Tribunais: São Paulo, 1970.

PIOVESAN, Flávia; IKAWA, Daniela (Org.). Direitos Humanos: Fundamento, proteção e implementação. Curitiba: Juruá, 2010.

RAMOS, André de Carvalho. Curso de Direitos Humanos. São Paulo: Saraiva, 2014. 630 p. 
WOJCIECHOWSKI, Paola Bianchi. Leis da Anistia e o Sistema Internacional de Proteção dos Direitos Humanos: Estudo Comparativo Brasil, Argentina e Chile. Curitiba: Juruá, 2013. 